\title{
Pengaruh Work-Life Policies terhadap Organizational Commitment Dimediasi Oleh Variabel Job Satisfaction pada Karyawan Tetap di Nico Course
}

\author{
Leonardo dan Yanuar \\ Program Studi Manajemen Fakultas Ekonomi dan Bisnis \\ Universitas Tarumanagara \\ Email: lauwleonardo7@gmail.com
}

\begin{abstract}
The purpose of this research is to analyze the influence of work-life policies towards organizational commitment mediated by job satisfaction variable. The population of this research is the 126 employee from Nico Course. Sample was selected non-probabilty sampling. Data processing techniques using structural equation modeling which assisted by SmartPLS version 3.2.9 program. The result of this study reveals that both work-life policies and job satisfaction have significant and positive effect towards organizational commitment and job satisfaction successfully mediated work-life policies and organizational commitment
\end{abstract}

Keywords: Work-life policies, Organizational Commitment, Job Satisfaction

Abstrak: Tujuan dari penelitian ini yaitu untuk mengetahui pengaruh work-life policies terhadap organizational commitment yang dimediasi oleh variabel job satisfaction. Populasi yang diambil dari penelitian ini adalah karyawan Nico Course yang berjumlah 126 orang. Sampel yang dipilih menggunakan non-probabilty samping bersifat purposive sampling berjumlah 100 orang. Teknik pengolahan data menggunakan structural equation modeling yang dibantu dengan program SmartPLS versi 3.2.9. Hasil dari penelitian ini adalah work-life policies dan job satisfaction berpengaruh secara signifikan dan positif terhadap organizational commitment dan job satisfaction berhasil memediasi antara work-life policies dan organizational commitment.

Kata kunci: Work-life policies, Komitmen Organisasi, Kepuasan Kerja

\section{LATAR BELAKANG}

Di era globalisasi ini organisasi semakin tertantang untuk dapat terus beradaptasi terhadap kemajuan dan teknologi yang ada dan menyebabkan organisasi-organisasi yang terjadi disegala komponen, salah satunya adalah sumber daya manusia. Untuk menyesuaikan dengan segala persaingan yang ada yang ada, organisasi mencari pekerja dengan komitmen yang tinggi untuk organisasi agar organisasi dapat terus bersaing dengan organisasi lain yang ada. Menurut Greenhaus dan Powell (2016) hal pertama yang harus diperhatikan oleh perusahaan adalah mencari cara apa yang paling efektif agar perusahaan dapat mendapatkan pekerja dengan tingkat komitmen yang tinggi, yang dimana salah satunya adalah work-life policies dan memperhatikan job satisfaction yang dimiliki para pekerja, cara ini melibatkan kemampuan SDM yang handal sebagai kunci agar para pekerja dapat memiliki tingkat komitmen yang tinggi kepada organisasi, yang merupakan salah satu faktor keunggulan yang dimiliki organisasi tersebut.

Di antara banyak persyaratan yang dapat berkontribusi pada kepuasan kerja dan komitmen organisasi karyawan, menyeimbangkan tanggung jawab pekerjaan dan keluarga bukanlah hal yang kecil. Hubungan kerja-keluarga yang negatif dapat membahayakan upaya manajemen sumber daya manusia yang mengembangkan karyawan yang berkomitmen yang berkontribusi pada keunggulan kompetitif perusahaan. Selain perspektif konflik yang lebih 
dikenal, ada satu lagi yang juga membantu menjelaskan hubungan antara kebijakan kerjakeluarga dan kepuasan kerja karyawan dan komitmen organisasi, tetapi kurang diuji secara empiris Mcnall et al., (2010). Perspektif ini adalah pengayaan yang merupakan lawan dari konflik, tidak menekankan bahwa kegiatan berbagi (bekerja dan keluarga) senantiasa menghambat pelatihan tetapi ada dampak positif juga. Namun, studi empiris jarang menggabungkan pengayaan dan konflik dan penulis belum menemukan analisis multivariat tentang pengayaan, konflik, dan kepuasan kerja karyawan dan komitmen organisasi. Kelangkaan studi semacam ini dapat menjelaskan hasil yang tidak meyakinkan yang ditemukan dalam literatur.

Sekalipun banyak faktor yang mempengaruhi organizational commitment, namun dalam studi yang dilakukan oleh Novelia (2013) menemukan bahwa tidak ada hubungan yang signifikan antara work-life policies (melalui work-life balance) dengan organizational commitment. Oleh karena itu akan ada pemikiran bagaimana cara menghilangkan gap yang ada pada penelitian tersebut.

\section{KAJIAN TEORI}

Menurut Sanchez et al., (2015) work-life policies adalah program apa pun yang meningkatkan kemampuan organisasi untuk mengintegrasikan kebutuhan pekerjaan dan kehidupan pribadi (perawatan diri, perawatan kesehatan, perawatan anak, perawatan lansia, perawatan mitra domestik, pendidikan dan studi, minat kehidupan pribadi). Work-life policies melampaui pengertian tradisional "ramah keluarga" yang terutama menyiratkan perawatan untuk anak-anak dan orang lain. Work-life policies memiliki banyak bentuk, ada praktik berbasis waktu yang dikenal sebagai jadwal kerja alternatif seperti kompresi atau waktu lembur dan pengurangan jadwal kerja seperti paruh waktu.

Menurut Kreitner \& Kinicki (2014) mengatakan bahwa job satisfaction atau kepuasan kerja adalah sebuah keadaan emosional yang positif dan menyenangkan yang dihasilkan dari penilaian atau pendapat sesseorang terhadap suatu pekerjaan atau pengalaman kerja seseorang.

Griffin (2016) menyatakan bahwa komitmen organisasi adalah sebuah hal yang menjadi keyakinan bagi para pekerja untuk merasa terikat dengan organisasi tempatnya bekerja, yang ditunjukkan dengan adanya loyalitas, keterlibatan dalam pekerjaan, dan identifikasi terhadap nilai dan tujuan yang dimiliki organisasi.

Dalam penelitian yang dilakukan oleh Silva, Dutra, Veloso, Fischer dan Trevisan (2020) yang didukung dengan penelitian dari Pradhan, Jena dan Kumari (2018) menyatakan adanya hubungan positif yang signifikan antara work-life policies dan organizational commitment dikarenakan ketika work-life policies dapat menyesuaikan keaadaan dan tercapai work-life balance sehingga dapat memberikan kontribusi untuk keterlibatan pekerja (kepuasan kerja dan komitmen organisasi) yang nanti pada gilirannya akan memberikan kontribusi produktivitas yang lebih tinggi dengan tingkat turnover yang lebih rendah.

Tapi dalam penelitian yang dilakukan oleh Sanchez et al., (2018) menyatakan bahwa ketika diuji dengan berbagai item yang mempengaruhi organizational commitment, work-life policies bukanlah hal yang terlalu berpengaruh dalam menentukan komitmen yang dimiliki pekerja kepada organisasi tersebut. Hal serupa juga dinyatakan dalam penelitian yang dilakukan oleh Novelia (2013) yang menyatakan tidak adanya hubungan yang signifikan antara work-life policies yang diteliti melalui work-life balance dengan organizational commitment dari item PLIW (personal life interference with work). Hal ini disebabkan terutama karena kedua faktor ini tidak berhubungan secara langsung, banyak faktor yang ikut mempengaruhi hubungan kedua variabel tersebut. Contohnya kepuasan kerja, karakteristik pekerjaan dan lingkungan kerja itu sendiri. 
Dari uraian diatas, dapat disimpulkan bahwa sudah ada penelitian yang sudah lebih dulu mengenai work-life policies dan organizational commitment, dan hasilnya masih tidak konsisten. Jadi dalam penelitian ini, diharapkan dapat meneliti kedua faktor tersebut dengan hasil yang lebih konsisten dan empiris.

Menurut penelitian yang dilakukan oleh Parkes dan Langford (2008) menyatakan bahwa work-life policies yang berhasil, adanya budaya family friendly dan work-life balance yang tercapai, biasanya akan menunjukan hubungan yang positif juga terhadap job satisfaction, organizational commitment, citizenship dan keputusan untuk tetap bertahan di organisasi tersebut. Dari uraian dari hasil penelitian terdahulu diatas, dapat disimpulkan adanya hubungan yang signifikan dan positif antara work-life policies dengan job satisfaction.

Menurut Gibson, Ivancevich dan Donnaely (2012) menyatakan bahwa job satisfaction memiliki hubungan yang signifikan dan positif terhadap organizational commitment, pekerja yang puas terhadap pekerjaannya cenderung akan memiliki komitmen yang lebih tinggi dari mereka yang tidak merasakan kepuasan ini. Komitmen ini lah yang akan mempengaruhi apakah pekerja akan tetap bertahan atau meninggalkan organisasi. Berdasarkan uraian diatas, dapat disimpulkan bahwa adanya hubungan yang signifikan dan positif antara job satisfaction dengan organizational commitment.

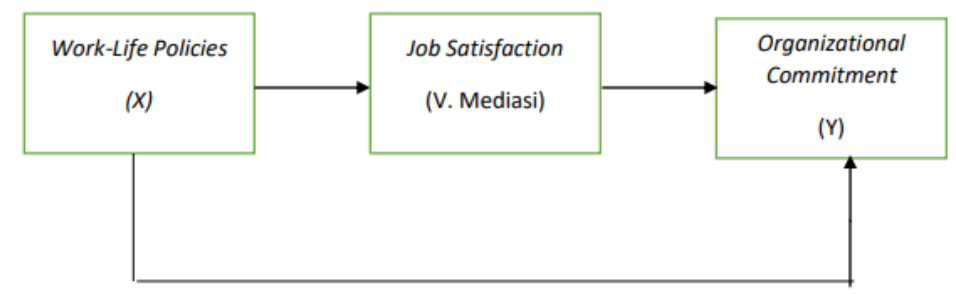

Gambar 1. Kerangka Pemikiran

H1 : Work-life policies mempunyai pengaruh terhadap organizational commitment

$\mathrm{H} 2 \quad$ : Work-life policies mempunyai pengaruh terhadap job satisfaction

H3 : Job satisfaction memiliki pengaruh terhadap organizational commitment

H4 : Job satisfaction memediasi hubungan antara work-life policies dan organizational commitment

\section{METODOLOGI}

Penelitian ini merupakan penelitian deskriptif. Populasi yang diambil pada penelitian ini adalah para pekerja tetap di Nico Course sebanyak 126 responden. Alasan dipilih pekerja tetap dari Nico Course adalah karena peneliti merasa work-life policies akan paling terasa efeknya bagi mereka yang bekerja secara penuh kepada sebuah organisasi, dan karena mereka bekerja secara penuh kepada organisasi tersebut apakah work-life policies yang sudah ditetapkan di organisasi tersebut sangat berpengaruh pada komitmen pekerja kepada organisasi tersebut (organizational commitment) dengan dimediasi dengan variabel job satisfaction.

\section{Hasil Uji Validitas}

Menurut Hair et al., (2014, h. 3) validitas digunakan untuk mengetahui sejauh mana serangkaian pengukuran yang dilakukan dapat mewakilkan sebuah konsep studi. Dalam penelitian ini, instrument penguji validitas dalam PLS terdiri atas nilai Outer Loading dan Average Variance Extracted (AVE), dan uji validitas diskriminan diukur dengan Fornell- 
Lacker Criterion dan Cross Loading. Hasil dari instrumen pengujian akan diuraikan sebagai berikut:

Tabel 1. Hasil Factor Loading (Outer Loading)

\begin{tabular}{|c|c|c|c|c|}
\hline Indikator & Work-life policies & $\begin{array}{c}\text { Job } \\
\text { Satisfaction }\end{array}$ & $\begin{array}{c}\text { Organizational } \\
\text { Commitment }\end{array}$ & Keterangan \\
\hline WLP1 & 0.754 & & & Valid \\
\hline WLP2 & 0.826 & & & Valid \\
\hline WLP3 & 0.851 & & & Valid \\
\hline WLP4 & 0.748 & & & Valid \\
\hline JS1 & & 0.806 & & Valid \\
\hline JS2 & & 0.847 & & Valid \\
\hline JS3 & & 0.736 & & Valid \\
\hline JS4 & & 0.715 & & Valid \\
\hline JS5 & & 0.822 & & Valid \\
\hline OC1 & & & 0.766 & Valid \\
\hline OC2 & & & 0.787 & Valid \\
\hline OC3 & & & 0.809 & Valid \\
\hline OC4 & & & 0.765 & \\
\hline
\end{tabular}

Sumber Olahan Data: SMART PLS versi 3.29

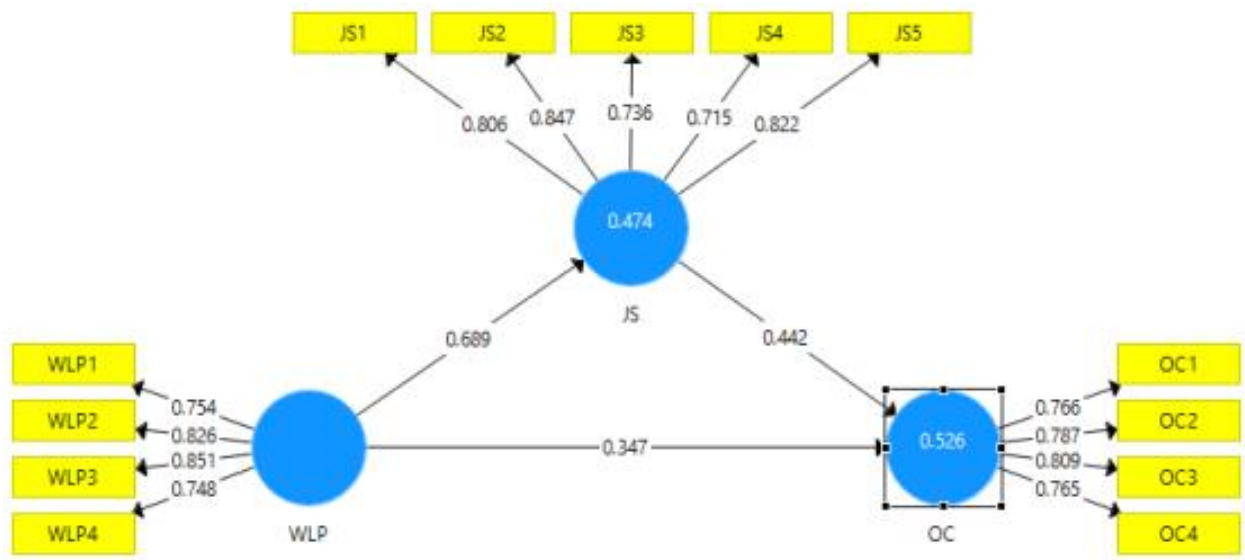

Gambar 2. Output Outer Loading

Berdasarkan tabel 1 dan gambar 2 dapat diuraikan bahwa hasil dari masing-masing indikator memiliki nilai factor loading > 0,5 (Hair et al., 2014, h, 110) dimana setiap indikator memenuhi syarat sehingga dinyatakan valid dan signifikan.

\section{Hasil Uji Reliabilitas}

Instrumen uji reliabilitas pada PLS menggunakan cronbach's alpha dan composite reliability. Berikut tabel hasil uji reliabilitas menggunakan composite reliability:

Tabel 2

\begin{tabular}{|c|c|c|c|}
\hline Variabel & Cronbach's Alpha & Composite Reliability & Keterangan \\
\hline Work-life policies & 0.806 & 0.873 & Reliabel \\
\hline Job Satisfaction & 0.847 & 0.890 & Reliabel \\
\hline Organizational Commitment & 0.788 & 0.863 & Reliabel \\
\hline
\end{tabular}


Sumber olahan data: SMART PLS versi 3.0

Berdasarkan tabel diatas, dapat diuraikan bahwa nilai cronbach's alpha untuk masingmasing variabel adalah reliabel signifikan dikarenakan memenuhi standar peneliaian cronbach's alpha sebesar < 0,7 (Hair et al., 2014) dan dapat diuraikan bahwa setiap variabel dinyatakan reliabel dikarenakan mencapai nilai standar koefisien Composite Reliability sebesar >0.80 (Hair et al., 2014).

\section{Uji Koefisien Determinasi $\left(\mathbf{R}^{2}\right)$}

Menurut Hair et al., (2014, h. 206) R square adalah korelasi kuadrat atau disebut sebagai koefisien determinasi. Nilai R square sebesar 0.67 dinyatakan kuat, 0.33 dinyatakan moderat dan 0.19 dinyatakan lemah

Tabel 3

\begin{tabular}{|c|c|}
\hline Variabel & $R$ Square \\
\hline Job Satisfaction & 0.474 \\
\hline Organizational Commitment & 0.526 \\
\hline
\end{tabular}

Sumber Olahan Data: SMART PLS versi 3.29

Berdasarkan dengan tabel 3 diuraikan apabila work-life policies mempunyai pengaruh moderat (sedang) terhadap job satisfaction sebesar 0,474. Maka, apabila work-life policies mengalami perubahan, job satisfaction juga akan mengalami perubahan sebesar $47,4 \%$. Sedangkan job satisfaction mempunyai pengaruh moderat (sedang) terhadap organizational commitment sebesar 0,526. Artinya, apabila adanya perubahan pada job satisfaction, maka organizational commitment akan mengalami perubahan juga sebesar 52.6\%.

\section{Hasil Uji Q Square}

Hasil uji Q square diperoleh melalui proses blindfolding dimana blindfolding itu sendiri diterapkan untuk variabel yang dipengaruhi menggunakan model pengukuran reflektif. Berikut hasil uji Q square:

Tabel 4

\begin{tabular}{|c|c|}
\hline Variabel & $Q$ square \\
\hline Job Satisfaction & 0.274 \\
\hline Organizational Commitment & 0.304 \\
\hline
\end{tabular}

Sumber Olahan Data: SMART PLS versi 3.29

Berdasarkan tabel 4 dapat diuraikan bahwa hasil dari masing-masing variabel menunjukkan adanya relevansi prediktif dikarenakan nilai Q square yang diperoleh $>0$ (Hair et al., 2014).

\section{Path Coefficient}

Tabel 5

\begin{tabular}{|c|c|c|}
\hline Variabel & Job Satisfaction & $\begin{array}{c}\text { Organizational } \\
\text { Commitment }\end{array}$ \\
\hline Work-life policies & 0.689 & 0.347 \\
\hline Job Satisfaction & & 0.442 \\
\hline
\end{tabular}

Sumber Olahan Data: SMART PLS versi 3.29 
Berdasarkan dengan tabel diatas dapat diuraikan bahwa hasil path coefficient menunjukkan work-life policies mempunyai pengaruh terhadap job satisfaction sebesar 0,689. Hasil path coefficient menunjukkan work-life policies mempnuayi pengaruh terhadap organizational commitment sebesar 0,347. Hasil path coefficient menunjukan job satisfaction mempunyai pengaruh terhadap organizational commitment sebesar 0,442.

\section{Hasil Uji F Square}

Tabel 6

\begin{tabular}{|l|c|}
\hline \multicolumn{1}{|c|}{ Variabel } & $\begin{array}{c}\text { Nilai } F \\
\text { Square }\end{array}$ \\
\hline Work-life policies $\rightarrow$ Organizational Commitment & 0.133 \\
\hline Work-life policies $\rightarrow$ Job Satisfaction & 0.901 \\
\hline Job Satisfaction $\rightarrow$ Organizational Commitment & 0.217 \\
\hline
\end{tabular}

Sumber Olahan Data: SMART PLS versi 3.29

Berdasarkan tabel 6 dapat diuraikan sesuai dengan ketentuan nilai $F$ square yaitu 0,02 mewakili efek kecil, 015 mewakili efek sedang, dan 0,35 mewakili efek besar (Hair et al., 2014). Maka hasil uji $f$ square pada tabel 4.29 dijelaskan bahwa Variabel work-life policies mempunyai efek kecil terhadap nilai $f$ square variabel organizational commitment sebesar 0,133 . Variabel work-life policies mempunyai efek besar terhadap nilai $f$ square variabel job satisfaction sebesar 0,901. Variabel job satisfaction mempunyai efek sedang terhadap nilai $f$ square variabel organizational commitment sebesar 0,217.

\section{Hasil Uji Hipotesis}

Untuk mengetahui hasil hipotesis dari masing-masing variabel dalam suatu penelitian, dalam PLS dapat dilihat dari hasil $t$ statistics dan $P$ values yang dimana menjelaskan setiap variabel beserta tingkat signifikansinya. $P$ values dapat didapatkan nilainya dengan menggunakan metode bootstrapping pada PLS.

\section{Hasil uji $T$ statistics dan $P$ values}

Tabel 7

\begin{tabular}{|l|c|c|}
\hline \multicolumn{1}{|c|}{ Variabel } & T statistics & P Values \\
\hline Work-life policies $\rightarrow$ Organizational Commitment & 3.195 & 0,001 \\
\hline Work-life policies $\rightarrow$ Job Satisfaction & 14.073 & 0,000 \\
\hline Job Satisfaction $\rightarrow$ Organizational Commitment & 5.155 & 0,000 \\
\hline $\begin{array}{l}\text { Work-life policies } \rightarrow \text { job satisfaction } \rightarrow \text { organizational } \\
\text { commitment }\end{array}$ & 4.723 & 0.000 \\
\hline
\end{tabular}

Sumber Olahan Data: SMART PLS versi 3.29 


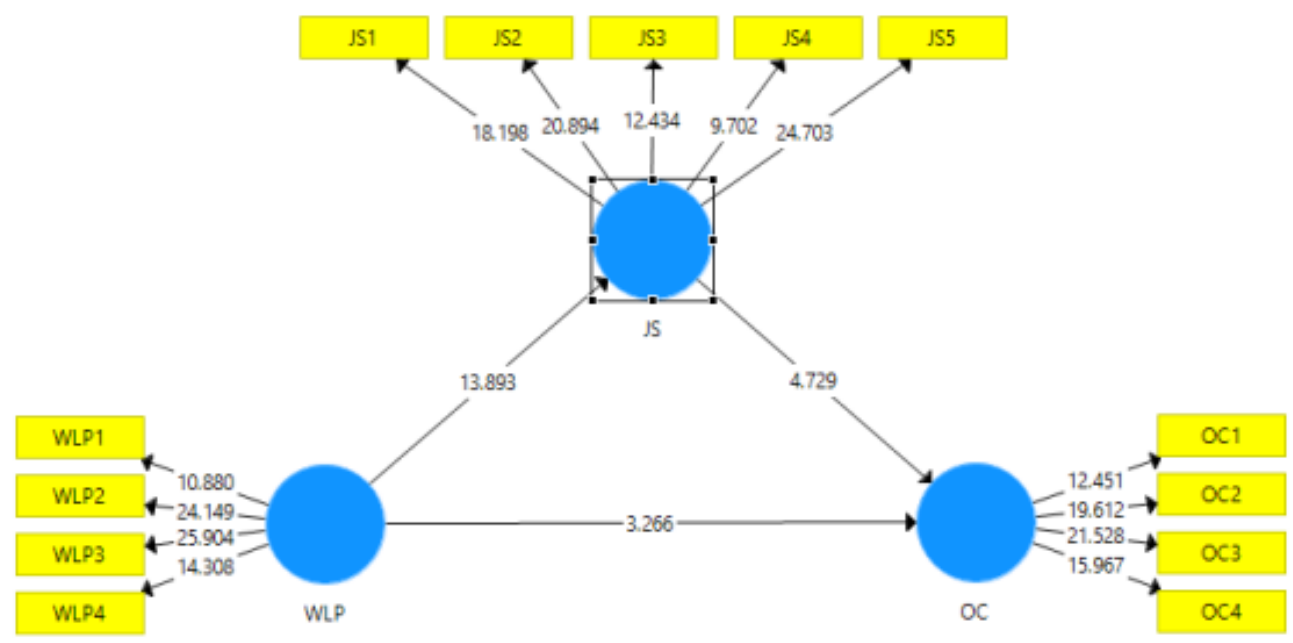

Gambar 3. Output Path Coefficient berikut:

Berdasarakan tabel 7 dan gambar 3, dapat diuraikan hasil pengujian hipotesis sebagai

\section{H1: Work-life policies mempunyai pengaruh terhadap organizational commitment.}

Berdasarkan dengan tabel 7, variabel work-life policies mempunyai pengaruh terhadap organizational commitment dengan hasil $t$ statistics sebesar 3.195 dengan nilai $p$ values sebesar 0,001. Maka, hipotesis satu (H1) diterima karena $t$ statistics $>1,96$ dengan $p$ values $<$ 0,05. Jadi, work-life policies mempunyai pengaruh yang positif dan signifikan terhadap organizational commitment.

\section{H2: Work-life policies mempunyai pengaruh terhadap job satisfaction.}

Berdasarkan dengan tabel 7 , variabel work-life policies mempunyai pengaruh terhadap job satisfaction dengan hasil $t$ statistics sebesar 14.073 dengan $p$ values sebesar 0,000 . Maka. hipotesis kedua (H2) diterima, Karena hasil $t$ statistics $>1,96$ dengan $p$ values $<0,05$. Jadi, work-life policies mempunyai pengaruh yang positif dan signifikan terhadap job satisfaction.

\section{H3: Job satisfaction mempunyai pengaruh terhadap organizational commitment.}

Berdasarakan tabel 7, variabel job satisfaction mempunyai pengaruh terhadap organizational commitment dengan hasil $t$ statistics sebesar 5.155 dengan $p$ values sebesar 0,000. Maka, hipotesis ketiga (H3) diterima, karena hasil $t$ statistic $>1,96$ dengan $p$ values $<$ 0,05 . Jadi job satisfaction mempunyai pengaruh yang positif dan signifikan terhadap organizational commitment.

\section{H4: Job satisfaction memediasi hubungan antara work-life policies dan organizational commimtment}

Berdasarkan dengan hasil pengujian variabel job satisfaction memediasi hubungan antara work-life policies dan organizational commitment menghasilkan $t$ statistics sebesar 4.723 dengan $p$ values sebesar 0,000. Maka, hipotesis keempat (H4) diterima, dikarenakan hasil pengujian $t$ statistics lebih besar dari 1,96 dengan $p$ values kurang dari 0,05. Jadi variabel job satisfaction dapat memediasi sepenuhnya hubungan antara work-life policies dan organizational commitment.

\section{DISKUSI}

Berdasarkan hasil dari pengujian hipotesis dengan menggunakan metode bootstrapping dengan pengujian path coefficient, indirect effect. Hasil pengujian path coefficient setelah 
menggunakan bootstrapping menunjukkan bahwa hasil pengujian untuk hipotesis satu (H1) yaitu work-life policies mempunyai pengaruh terhadap organizational commitment dengan hasil $t$ statistics sebesar 3.195 dengan $p$ value sebesar 0,001. Maka, hipotesis satu diterima dan signifikan karena telah memenuhi nilai $t$ statistics yaitu $>1,96$ dengan $p$ value $<0,05$. Hasil pengujian hipotesis kedua (H2) yaitu work-life policies mempunyai pengaruh terhadap job satisfaction dengan hasil $t$ statistics sebesar 14.073 dengan $p$ value sebesar 0,000 . Maka hipotesis dua diterima dan signifikan dikarenakan telah memenuhi nilai $t$ statistics dengan $p$ value. Hasil pengujian hipotesis ketiga $(\mathrm{H} 3)$ yaitu job satisfaction mempunyai pengaruh terhadap organizational commitment dengan hasil $t$ statistics sebesar 4,91 dengan $p$ value 0,000. Maka hipotesis ketiga diterima dan signfikan dikarenakan telah memenuhi nilai $t$ statistic dan $p$ value. Berdasarkan hasil pengujian mediasi menunjukkan bahwa hipotesis keempat (H4) yaitu job satisfaction memediasi hubungan antara work-life policies dan organizational commitment dengan hasil $t$ statitistic sebesar 4.653 dengan $p$ values sebesar 0,000. Maka, hipotesis keempat diterima, dikarenakan telah memenuhi penilaian $t$ statistic dengan $p$ value. Maka, job satisfaction sepenuhnya mendukung dan dapat memediasi hubungan antara work-life policies dan organizational commitment. Apabila work-life policies suatu perusahaan dikatakan menarik, maka kepuasan yang akan dirasakan karyawan akan meningkat terutama apabila work-life policies yang diberikan sesuai dengan keinginan atau atas pertimbangan dari masukan para karyawan. Dengan begitu dapat meningkatkan organizational commitment.

\section{PENUTUP}

Dari hasil penelitian yang dilakukan terdapat beberapa saran yang diberikan untuk perusahaan yaitu untuk mempertimbangkan hal-hal yang diinginkan para karyawan. Sesuai dengan penelitian untuk work-life policies, indikator "organisasi menyediakan berbagai pendukung transportasi mulai dari uang bensin sampai kendaraan pribadi" adalah yang terendah. Oleh sebab itu, hal yang bersangkutan dengan transportasi perlu lebih diperhatikan dan ditingkatkan lagi oleh perusahaan. Lalu untuk variabel job satisfaction, indikator "rekan kerja yang selalu mendukung baik perihal pekerjaan maupun non-pekerjaan" adalah yang terendah. Oleh sebab itu, perusahaan harus lebih memperhatikan proses seleksi sehingga karyawan yang terpilih bukan hanya mereka saja yang dinilai mampu menyelesaikan masalah, melainkan karyawan yang dapat bekerja dalam tim dan tidak hanya mementingkan dirinya sendiri. Untuk variabel organizational commitment, indikator "saya merasa sebagai 'keluarga' di perusahaan ini" adalah yang terendah. Oleh sebab itu perusahaan harus memandang karyawannya sebagai sebuah aset yang harus dijaga bukan hanya sekedar sumber daya yang disewa untuk menyelesaikan masalah yang dimiliki oleh perusahaan.

\section{DAFTAR PUSTAKA}

Batvandi, Z., \& Ghazavi, M. (2017). the Quality of Working Life with Organizational Commitment and Job Satisfaction. 6, 100-110.

Bui, H. T. M., Liu, G., \& Footner, S. (2016). Perceptions of HR practices on job motivation and work-life balance: Mixed drives and outcomes in a labor-intensive sector. International Journal of Manpower, 37(6), 1004-1023. https://doi.org/10.1108/IJM12-2015-0214

Chummar, S., Singh, P., \& Ezzedeen, S. R. (2019). Exploring the differential impact of work passion on life satisfaction and job performance via the work-family interface. Personnel Review, 48(5), 1100-1119. https://doi.org/10.1108/PR-02-2017-0033 
El Badawy, T. A., Chinta, R., \& Magdy, M. M. (2018). Does 'gender' mediate or moderate the relationship between 'quality of work life' and 'organizational commitment'?: Evidence from SMEs in Egypt. Gender in Management, 33(4), 332-348. https://doi.org/10.1108/GM-04-2017-0050

GIBSON, J. L., IVANCEVICH, J. M., DONNELLY, J. H., \& KONOPASKE, R. (2012). Organizations: behavior, structure, processes. New York, McGraw-Hill.

Greenhaus, J., \& Powell, G. N. (2016). Making Work and Family Work: From hard choices to smart choices. In Making Work and Family Work: From Hard Choices to Smart Choices. https://doi.org/10.4324/9781315780511

Griffin, R., Phillips, J., \& Gully, S. (2016). Organizational Behavior: Managing People and Organizations.

Henry, H., \& Desmette, D. (2018). Work-family enrichment and well-being: the role of occupational future time perspective. Career Development International, 23(6-7), 542-556. https://doi.org/10.1108/CDI-02-2018-0043

Jena, L. K., \& Pradhan, S. (2018). Workplace spirituality and employee commitment: The role of emotional intelligence and organisational citizenship behaviour in Indian organisations. Journal of Enterprise Information Management, 31(3), 380-404. https://doi.org/10.1108/JEIM-10-2017-0144

Kraak, J. M., Russo, M., \& Jiménez, A. (2018). Work-life balance psychological contract perceptions for older workers. Personnel Review, 47(6), 1198-1214. https://doi.org/10.1108/PR-10-2017-0300

Kuruüzüm, A., Çetin, E. I., \& Irmak, S. (2009). Path analysis of organizational commitment, job involvement and job satisfaction in Turkish hospitality industry. Tourism Review, 64(1), 4-16. https://doi.org/10.1108/16605370910948821

Martinez-Sanchez, A., Perez-Perez, M., Vela-Jimenez, M. J., \& Abella-Garces, S. (2018). Job satisfaction and work-family policies through work-family enrichment. Journal of Managerial Psychology, 33(4-5), 386-402. https://doi.org/10.1108/JMP-10-20170376

Mcnall, L., Nicklin, J., \& Masuda, A. (2010). A Meta-Analytic Review of the Consequences Associated with Work-Family Enrichment. Journal of Business and Psychology, 25, 381-396. https://doi.org/10.1007/s10869-009-9141-1

Mercurio, Z. (2015). Affective Commitment as a Core Essence of Organizational Commitment: An Integrative Literature Review. Human Resource Development Review, 14. https://doi.org/10.1177/1534484315603612

Mungkasa, O. (2020). Bekerja Jarak Jauh (Telecommuting): Konsep, Penerapan dan Pembelajaran. Bappenas Working Papers, III(1), 1-32. http://workingpapers.bappenas.go.id/index.php/bwp/article/view/52

Novelia, P. (2013). Hubungan Antara Work / Life Balance Dan Komitmen. 2008, 1-19.

Parkes, L., \& Langford, P. (2008). Work-Life Balance or Work-Life Alignment? A test of the importance of work-life balance for employee engagement and intention to stay in organisations. Journal of Management \& Organization, 14, 267-284. https://doi.org/10.5172/jmo.837.14.3.267

R. Helmle, J., C. Botero, I., \& R. Seibold, D. (2014). Factors that influence perceptions of work-life balance in owners of copreneurial firms. Journal of Family Business Management, 4(2), 110-132. https://doi.org/10.1108/JFBM-06-2014-0013

Rene, R. (2018). Pengaruh Work-Life Balance Terhadap Komitmen Organisasi, Kepuasan Kerja, Dan Motivasi Kerja. 16(4).

Ringle, Christian M., Wende, Sven, \& Becker, Jan-Michael. (2015). SmartPLS 3. Bönningstedt: SmartPLS. Retrieved from http://www.smartpls.com

Robbins, S. P., \& Judge, T. A. (2017). Organizational Behavior, Global Edition. 747. 
Sehgal, A. (2014). Book Review: Debra L. Nelson, James Campbell Quick and Preetam Khandelwal, Organizational Behaviour: A South Asian Perspective. Vision, 18(2), 145-146. https://doi.org/10.1177/0972262914528603

Sekaran, U., \& Bougie, R. (2016). Research Methods for Business : A Skill Building Approach Seventh Edition. In John WIley \& Sons. https://doi.org/10.1007/978-94007-0753-5_102084

Silva, R., Dutra, J., Veloso, E. F. R., \& Trevisan, L. (2020). Leadership and performance of Millennial generation in Brazilian companies. Management Research. https://doi.org/10.1108/MRJIAM-02-2019-0910

Sugiyono. (2016). Metode Penelitian: Kuantitaf, Kualitatif, dan $R \&$ D. Bandung: Alfabeta.

Tumewu, F. (2017). a Qualitative Study of Employeesâ Work-Life Balance and Organizational Commitment At Pt Bank Mandiri (Persero) Tbk Manado. Jurnal EMBA: Jurnal Riset Ekonomi, Manajemen, Bisnis Dan Akuntansi, 5(3), 2948-2957. https://doi.org/10.35794/emba.v5i3.17225

X-ers, G. (2017). Study of work-family and family-work conflicts overturns generational stereotypes. Human Resource Management International Digest, 25(7), 42-44. https://doi.org/10.1108/HRMID-08-2017-0143

Yousaf, A., Yang, H., \& Sanders, K. (2015). Effects of intrinsic and extrinsic motivation on task and contextual performance of Pakistani professionals. In Journal of Managerial Psychology (Vol. 30, Issue 2). https://doi.org/10.1108/JMP-09-2012-0277 